\title{
Investigations on renal vascularisation pathology in the Polish population. 1. Incidence of multiple kidney arteries
}

\author{
H. Sośnik, K. Sośnik \\ Department of Pathomorphology, Regional Specialist Hospital, Wroclaw, Poland \\ [Received: 12 September 2016; Accepted: 4 November 2016]
}

\begin{abstract}
Background: The aim of the study was to determine the incidence of multiple kidney arteries in the Polish population.

Materials and methods: The study group comprised 924 deceased patients aged between 1 month and 94 years (mean age: $63.4 \pm 22.4$ years) who were subject to aortonephrography and sample preparation. The ratio of male to female patients was 479:445.

Results: Multiple kidney arteries were observed in $44.8 \%$ male and $31.5 \%$ female patients ( $p=0.004$ ). Considering male patients, right multiple kidney arteries were diagnosed in $24.4 \%$, and left multiple kidney arteries in $31.3 \%$ of cases $(p=0.017)$. In female patients, right multiple kidney arteries were observed in $17.8 \%$ of cases, and left multiple kidney arteries in $19.6 \%$ of cases $(p=0.49$ ).

Conclusions: The incidence of multiple kidney arteries in the Polish population is a frequent phenomenon, and should be considered in case of urological surgery and kidney transplantation. (Folia Morphol 2017; 76, 2: 226-231)
\end{abstract}

Key words: multiple kidney arteries, aortonephrography, Polish population

\section{INTRODUCTION}

Additional kidney arteries are essentially segmentary renal arteries with direct branching from the aorta or iliac arteries [14]. They occur much more frequently than expected, ranging between $7.8 \%$ and $39 \%[2,8,10,15,18,21-24,34,36,38]$. They can have adverse implications during urological procedures, treatment of arteriorenal hypertension, and kidney transplantation [32, 33]. Considering one of the studies from 1998, preoperative angiography showed no presence of additional renal arteries in $7 \%$ of kidneys collected from living donors [17]. In selected cases of postmortem kidney donors the polar arteries were not recognised, and severed or damaged by the transplantologist [31]. The angiographic find- ings before surgery were in only $95-97 \%$ of cases in accordance with the intraoperative situation $[6,28]$. Multiple kidney arteries are one of the most difficult conditions considering laparoscopic renal donors [20]. Therefore, knowledge of the above-mentioned issue seems important for the surgeon, in order to avoid clinical complications [3, 9].

In 1975, Hall et al. [16] suggested that the postmortem kidney donor should be well-ventilated, being aged between 6 and 50 years, and have only one artery. The aging human population and continuous, increased demand for kidney transplantation have forced the liberalisation of the above-mentioned principles, which is particularly important considering that renal transplantation surgery is the therapeutic

Address for correspondence: H. Sośnik, MD, PhD, Department of Pathomorphology, Regional Specialist Hospital, ul. Jaracza 82 B/4, 50-305 Wrocław, Poland, tel: +48 7179141 29, e-mail: henryksosnik@gmail.com 


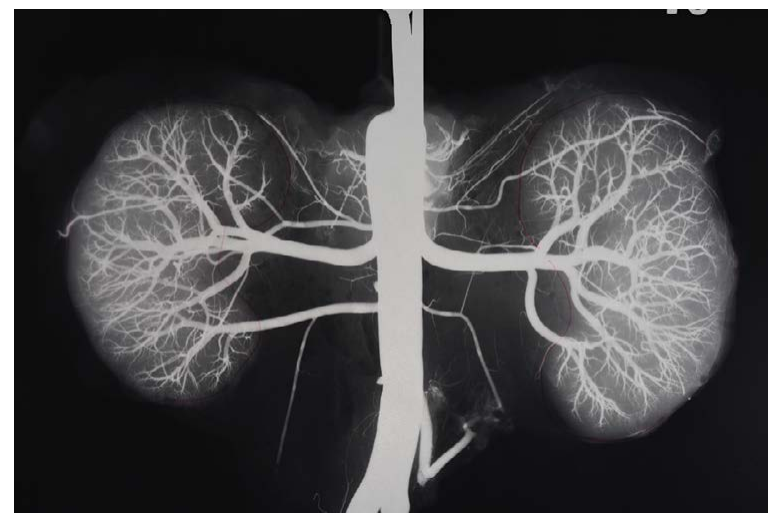

Figure 1. Postmortem aortonephrogram with visualisation of an additional right renal artery.

method of choice in patients with end-stage renal failure $[13,19]$.

The genesis of multiple kidney artery formation remains unknown. Satyapal et al. [34] suggested the influence of race as one of the possible factors. In the presented study we tried to determine the above-mentioned problem in the Polish population.

\section{MATERIALS AND METHODS}

The study group comprised 924 arteriorenal preparations collected from fresh deceased patients, including 479 male and 445 female subjects. Male patient age ranged between 1 month and 91 years (mean age: $51.2 \pm 22.2$ years), while female patient age between 1 month and 94 years (mean age: $55.8 \pm 22.5$ years) $(p=0.002)$. In 377 cases, aortonephrographic examinations were performed as follows: the kidneys with their arteries and aorta were excised "en bloc". After vascular ligation a $30 \%$ solution of barium sulphate was introduced into the aorta. The solution was placed on the X-ray tape, $35.6 \times 35.6 \mathrm{~cm}$ in size possessing $\mathrm{X}$-ray membranes manufactured by FOTON with a sensitivity of 125 CUK. The images (pictures) were performed using an X-ray with the following parameters: $65 \mathrm{kV}$ and $10 \mathrm{~mA}$. The exposition distance was $90 \mathrm{~cm}$. After taking the pictures (Fig. 1-3A) the anatomical specimen was placed into a $10 \%$ formalin solution for a period of 2 weeks. Afterwards, it was subject to preparation (Fig. 3B) with results presented on paper. Interesting cases were photographed. The study protocol considered the following features: examination

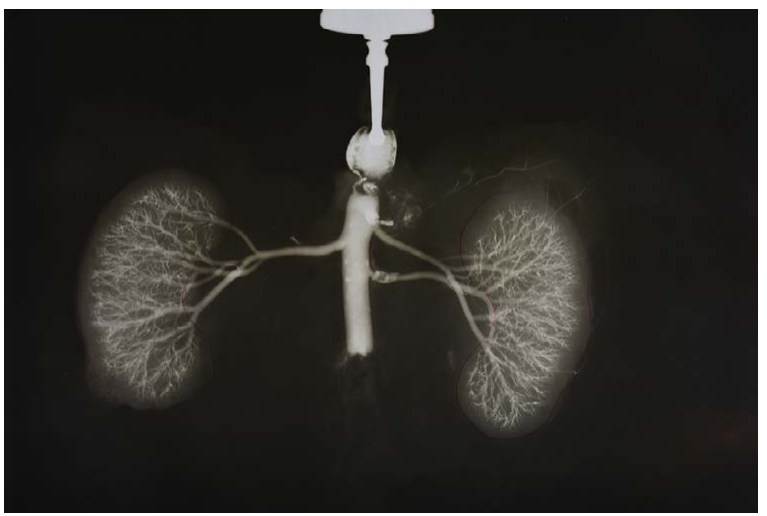

Figure 2. Postmortem aortonephrogram. The left additional renal artery branches of the aorta above the main kidney vessel crossing towards the lower part of the organ.
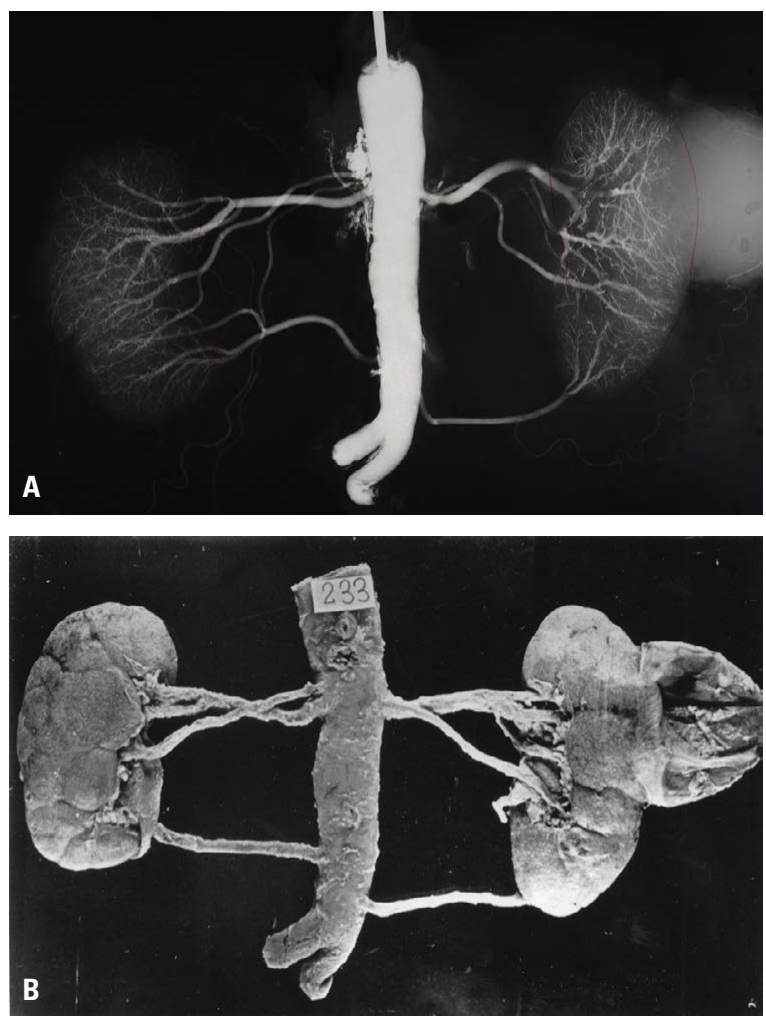

Figures 3. A, B. Postmortem aortonephrogram and its anatomical preparation. Bilaterally, the superior additional arteries cross the main vessels running towards the renal hilus, while the inferior additional arteries run towards the lower kidney poles beyond the renal pelvis.

number, age of the deceased, measurements of selected arteries, distances between them, and localisation of its branching from the aorta. The obtained data were subject to statistical analysis by means of STATISTICA 10 . 
Table 1. Multiple renal arteries in Polish population

\begin{tabular}{|c|c|c|c|c|c|c|c|c|}
\hline \multirow{2}{*}{$\begin{array}{l}\text { Number } \\
\text { of right renal } \\
\text { arteries }\end{array}$} & \multirow{2}{*}{$\begin{array}{c}\text { Number } \\
\text { of left renal } \\
\text { arteries }\end{array}$} & \multicolumn{2}{|c|}{ Males } & \multirow{2}{*}{$\begin{array}{l}\text { Renal } \\
\text { arteries' } \\
\text { patterns }\end{array}$} & \multicolumn{2}{|c|}{ Females } & \multirow{2}{*}{$\begin{array}{c}\text { Total } \\
\text { number }\end{array}$} & \multirow{2}{*}{$\begin{array}{c}\text { Total } \\
\text { percentage }\end{array}$} \\
\hline & & Number & Percentage & & Number & Percentage & & \\
\hline \multirow[t]{3}{*}{1} & 1 & 265 & $55.32 \%$ & $0+0$ & 305 & $68.54 \%$ & 570 & $61.69 \%$ \\
\hline & 2 & 88 & $18.37 \%$ & OFO & 58 & $13.03 \%$ & 146 & $15.80 \%$ \\
\hline & 3 & 9 & $1.88 \%$ & 010 & 3 & $0.67 \%$ & 12 & $1.30 \%$ \\
\hline \multirow[t]{4}{*}{2} & 1 & 56 & $11.69 \%$ & O月0 & 50 & $11.24 \%$ & 106 & $11.47 \%$ \\
\hline & 2 & 38 & $7.93 \%$ & $0 \neq 0$ & 20 & $4.49 \%$ & 58 & $6.28 \%$ \\
\hline & 3 & 1 & $0.21 \%$ & O邦 & 1 & $0.22 \%$ & 2 & $0.22 \%$ \\
\hline & 4 & 1 & $0.21 \%$ & O电 & 1 & $0.22 \%$ & 2 & $0.22 \%$ \\
\hline \multirow[t]{4}{*}{3} & 1 & 7 & $1.46 \%$ & $\mathrm{OAO}$ & 3 & $0.67 \%$ & 10 & $1.08 \%$ \\
\hline & 2 & 5 & $1.04 \%$ & OF & 3 & $0.67 \%$ & 8 & $0.87 \%$ \\
\hline & 3 & 5 & $1.04 \%$ & O㬰 & 0 & $0.00 \%$ & 5 & $0.54 \%$ \\
\hline & 4 & 1 & $0.21 \%$ & O用 & 0 & $0.00 \%$ & 1 & $0.11 \%$ \\
\hline \multirow[t]{2}{*}{4} & 1 & 1 & $0.21 \%$ & $\mathrm{OH} 0$ & 0 & $0.00 \%$ & 1 & $0.11 \%$ \\
\hline & 2 & 2 & $0.42 \%$ & OF & 1 & $0.22 \%$ & 3 & $0.32 \%$ \\
\hline Column sum & & 479 & $100.00 \%$ & & 445 & $100.00 \%$ & 924 & $100.00 \%$ \\
\hline
\end{tabular}

\section{RESULTS}

Based on the results presented in Table 1, only $61.7 \%$ of patients presented with the so-called "normal" renal vascular system, while $38.3 \%$ were diagnosed with multiple renal arteries. Amongst the above-mentioned patients, most frequently observed pattern was: 1 right renal artery and 2 left renal arteries (15.8\%). $11.5 \%$ of patients presented 2 right renal arteries and 1 on the left side. Bilateral 2 renal arteries were found in $6.3 \%$. Other variants in less than $1 \%$ of cases, apart from $1.08 \%$ with 3 right renal arteries and 1 on the left side.

Gender had significant influence on the occurrence of renal artery anomalies. Amongst 479 male patients, 214 (44.8\%) were diagnosed with multiple renal arteries, while amongst 445 female patients, only $140(31.5 \%)$ presented with multiple renal arteries $(p=0.0004)$.

In male patients, right-sided anomalies were observed in 117 (24.4\%) cases, while left-sided anomalies in $150(31.3 \%)$ cases ( $p=0.017)$. Considering female patients, right-sided anomalies were observed in $79(17.8 \%)$ cases, while left-sided anomalies in $87(19.6 \%)$ cases $(p=0.49)$.
Gender differences in terms of the side of the body were as follows: right-sided anomalies were observed in 117 (24.4\%) in male patients and in 79 (17.8\%) females $(p=0.013)$. Left-sided anomalies were observed in 150 (31.3\%) in male patients and in $87(19.6 \%)$ females $(p=0.0004)$.

The course of additional renal arteries and their relationship to the renal pelvis have clinical significance. Thorough analysis was undertaken regardless the course and calibre of the artery. However, the obtained results exceeded the volume content of the study, and therefore only selected percentages were presented. Among the 164 investigated additional arteries in male patients, $65.9 \%$ on the left side and $61.8 \%$ on the right side presented with a prepelvical course. On the other hand, $23.9 \%$ on the left and $32.9 \%$ on the right side exhibited a retropelvical course. The remaining arteries are the so-called polar vessels (arteriae polares renum). Among the 102 additional arteries in female patients, $67.3 \%$ on the left and $76.6 \%$ on the right side presented with a prepelvical course. On the other hand, $25.5 \%$ on the left and $14.9 \%$ on the right side exhibited a retropelvical course. The remaining were considered as polar arteries. 


\section{DISCUSSION}

In our study, we focused, similarly to Satyapal et al. [34], only on arteries branching of directly from the aorta or iliac arteries. Considering a large material of deceased patients, we observed a significant occurrence of multiple kidney arteries (38.3\%). Based on clinical investigations, the distortion of results was probably associated with the selection of the most favourable material for transplantation. Additionally, the authors present their results following analysis of the transplanted kidneys, and not the anthropological units of a given population. The quality of the obtained results might have also been influenced by the methodology and nomenclature used. It seemed that autopsy examinations might provide the most reliable results. We determined the above-mentioned phenomenon by comparing results obtained from 7 clinical investigations with 6 autopsy study results. Clinical investigations $[1,11,15,22,31,34,37]$ that comprised 3059 kidney transplants revealed 523 cases of multiple kidney arteries (17.1\%), with the prevalence rate ranging between $7.79 \%$ [22] and $31.4 \%$ [37]. On the other hand, in the autopsy material $[2,21,23,24,32,38], 213(18.7 \%)$ multiple renal arteries were diagnosed of the 1141 investigated kidneys, ranging between $2 \%$ [23] and 24.8\% [38]. Based on the above-mentioned data, the type of sampled material had no influence on the occurrence of multiple kidney arteries. Satyapal et al. [34] demonstrated some differences in the occurrence of multiple kidney arteries, depending on race. There is the question, however, whether in today's globalised world one can speak of race in the anthropological sense of the word, particularly taking into account that the same authors encountered problems, naming one of the subgroups "coloured". The presented material was too scarce to draw significant conclusions. Saldarriaga et al. [32] also analysed the above-mentioned phenomenon on a Colombian mestizo population (it meant Caucasian, Mongoloid, and Negroid racial phenotype mixture). Satyapal et al. [34] showed that $35.3 \%$ of white race subjects were diagnosed with renal vascular anomalies, which is similar to the results obtained in the investigations undertaken on Slavic subjects. On the other hand, in "Colombian mestizos", renal vascular anomalies were observed only in $24.8 \%$ of the samples [32].

Based on the review, it is impossible to draw clear anthropological conclusions regarding the influence of race on the occurrence of kidney arterial anoma- lies. Differences in the occurrence of kidney vascular anomalies might be influenced by many factors, such as the selection of the study material, number of patients, and reliability of the investigations. Reis and Esenther [29] presented results obtained from 500 deceased patients during student training from different American autopsy labs. Multiple renal arteries were diagnosed in $19.1 \%$ of cases. At the same time, they mentioned that small arteries might not have been noticed by the students.

Our study results demonstrated that $6.3 \%$ of patients were diagnosed with 4 renal arteries. However, patients with 5,6 or 7 renal arteries were rarely observed, mainly in the male population (0.21-1.0\%).

Gender may have an influence on the incidence of the above-mentioned vascular anomalies. It is believed that these kidney anomalies occur more often in males, as compared to female patients [18, 34]. Aragao et al. [2] investigated the human foetuses and showed only slight differences in the incidence of renal artery anomalies, between the male (11.7\%) and female $(10 \%)$ population.

In our investigations the incidence of the abovementioned kidney anomalies was greater in men, as compared to female patients $(44.7 \%$ and $31.8 \%$, respectively). These differences were especially visible when the left and right side of the body were compared. Left-sided kidney anomalies were diagnosed in $31.3 \%$ of male and $19.6 \%$ of female patients $(p=0.0004)$. Right-sided kidney anomalies were observed in $24.4 \%$ of male and $17.8 \%$ of female patients $(p=0.013)$. Our results are similar to those obtained by other authors [24, 28, 29, 32, 34]. Only Aragao et al. [2] showed right-sided predominance (11.7\% vs. $10 \%)$.

\section{CONCLUSIONS}

In conclusion, it is worth mentioning that the kidney during its early developmental stage ascends from the minor pelvis to the abdominal cavity, being subject to size and artery metamorphosis. Early in the embryogenesis the blood supply to the developing urogenital structures arises from the urogenital "rete arteriosum". Nine pairs of bilateral mesonephric arteries are present. Normally, the caudal branches of renal vessels undergo involution and disappear. Cranial arterial branches from the aorta become the persistent arteries. Finally, 1 artery undergoes bifurcation into 5 branches to particular kidney vascular segments. Aetiologically, multiple kidney arteries rep- 
resent mesonephric arteries. Hypothetically, a common embryonic error may underlie the formation of accessory renal arteries [5, 9, 11, 14, 27, 30, 35, 36]. However, for unknown reasons, this process is often incomplete and multiple kidney arteries not so rare [26]. Knowledge of the variety of renal arteries should be a beacon in such vascular procedures as therapeutic embolisation and angioplasty, as well as management of renal ischaemia during transplantation [7, 25]. Although multiple kidney artery transplants are burdened with some dose of risk, there is a consensus that the obtained results tend to be comparable to kidney transplantations with a single renal artery [1, 3, 12, 39]. Singh et al. [37] even performed partial laparoscopic nephrectomy in 333 patients with renal tumours, in which multiple renal arteries was not a particular problem. Definition of renal artery anomalies prior to operation could prevent an unnecessary loss of renal function in the postoperative period, and routine angiography and aortonephrography should be performed prior to every nephrectomy $[5,18,34]$.

\section{REFERENCES}

1. Amirzargar MA, Babolhavaeji $H$, Hosseini $S A$, et al. The new technique of using the epigastric arteries in renal transplantation with multiple renal arteries. Saudi J Kidney Dis Transpl. 2013; 24(2): 247-253, doi: 10.4103/13192442.109565, indexed in Pubmed: 23538346.

2. Aragão JA, de Oliveira Pacheco JM, Silva LA, et al. Frequency of multiple renal arteries in human fetuses. Surg Radiol Anat. 2012; 34(2): 133-136, doi:10.1007/s00276011-0860-4, indexed in Pubmed: 21814866.

3. Ashraf HS, Hussain I, Siddiqui AA, et al. The outcome of living related kidney transplantation with multiple renal arteries. Saudi J Kidney Dis Transpl. 2013; 24(3): 615-619, doi: 10.4103/1319-2442.111087, indexed in Pubmed: 23640649.

4. Bakirtas H, Guvence N, Eroglu M, et al. Surgical approach to cases with multiple renal arteries in renal transplantation. Urol Int. 2006; 76(2): 169-172, doi: 10.1159/000090883, indexed in Pubmed: 16493221.

5. Budhiraja V, Rastogi R, Anjankar V, et al. Renal artery variations: embryological basis and surgical correlation. Rom J Morphol Embryol. 2010; 51(3): 533-536, indexed in Pubmed: 20809032.

6. Chai JW, Lee W, Yin YHu, et al. CT angiography for living kidney donors: accuracy, cause of misinterpretation and prevalence of variation. Korean J Radiol. 2008; 9(4): 333-339, doi: 10.3348/kjr.2008.9.4.333, indexed in Pubmed: 18682671.

7. Chawla K, Gupta R, Singh HJ, et al. Bilateral bifid ureter with unilateral renal vasculature variations. Surg Radiol Anat. 2014; 36(4): 393-396, doi:10.1007/s00276-0131170-9, indexed in Pubmed: 23873247.
8. Chedid MF, Muthu C, Nyberg SL, et al. Living donor kidney transplantation using laparoscopically procured multiple renal artery kidneys and right kidneys. J Am Coll Surg. 2013; 217(1): 144-152, doi: 10.1016/j.jamcollsurg.2013.04.010, indexed in Pubmed: 23791283.

9. Ciçekcibaşi $A E$, Ziylan T, Salbacak A, et al. An investigation of the origin, location and variations of the renal arteries in human fetuses and their clinical relevance. Ann Anat. 2005; 187(4): 421-427, doi: 10.1016/j.aanat.2005.04.011, indexed in Pubmed: 16163857.

10. De Rosa P, Santangelo M, Scala A, et al. Difficult vascular conditions in kidney transplantation. Transplant Proc. 2006; 38(4): 1040-1043, doi:10.1016/j.transproceed.2006.03.073, indexed in Pubmed: 16757257.

11. el-Galley RE, Keane TE. Embryology, anatomy, and surgical applications of the kidney and ureter. Surg Clin North Am. 2000; 80(1): 381-401, xiv, indexed in Pubmed: 10685158.

12. Gawish $A E$, Donia $F$, Samhan $M$, et al. Outcome of renal allografts with multiple arteries. Transplant Proc. 2007; 39(4): 1116-1117, doi:10.1016/j.transproceed.2007.03.067, indexed in Pubmed: 17524906.

13. Ghazanfar A, Tavakoli A, Zaki MR, et al. The outcomes of living donor renal transplants with multiple renal arteries: a large cohort study with a mean follow-up period of 10 years. Transplant Proc. 2010; 42(5): 1654-1658, doi: 10.1016/j. transproceed.2009.12.067, indexed in Pubmed: 20620494.

14. Graves FT. The aberrant renal artery. J Anat. 1956; 90(4): 553-558, indexed in Pubmed: 13366870.

15. Hakim N, Aboutaleb E, Syed A, et al. A fast and safe living donor. Transplant Proc. 2010; 42(1): 165-170, doi: 10.1016/j.transproceed.2009.12.042, indexed in Pubmed: 20172306.

16. Hall CL, Sansom JR, Obeid M, et al. Agonal phase, ischaemic times, and renal vascular abnormalities and outcome of cadaver kidney transplants. Br Med J. 1975; 3(5985): 667-670, indexed in Pubmed: 1100186.

17. Han D, Choi S, Kim S. Microsurgical reconstruction of multiple arteries in renal transplantation. Transplant Proc. 1998; 30(7): 3004-3005, doi: 10.1016/s00411345(98)00905-1, indexed in Pubmed: 9838323.

18. Harrison LH, Flye MW, Seigler HF. Incidence of anatomical variants in renal vasculature in the presence of normal renal function. Ann Surg. 1978; 188(1): 83-89, indexed in Pubmed: 352280.

19. Johnson JE, Loveday EJ, Archer LJ, et al. Preoperative evaluation of live renal donors using multislice CT angiography. Clin Radiol. 2005; 60(7): 771-777, doi: 10.1016/j. crad.2004.12.007, indexed in Pubmed: 15978888.

20. Kacar S, Gurkan A, Akman F, et al. Multiple renal arteries in laparoscopic donor nephrectomy. Ann Transplant. 2005; 10: 34-37.

21. Khamanarong K, Prachaney $P$, Utraravichien A, et al. Anatomy of renal arterial supply. Clin Anat. 2004; 17(4): 334-336, doi: 10.1002/ca.10236, indexed in Pubmed: 15108340.

22. Kumar A, Gupta RS, Srivastava A, et al. Sequential anastomosis of accessory renal artery to inferior epigastric artery in the management of multiple arteries in live related renal transplantation: a critical appraisal. Clin Transplant. 2001; 15(2): 131-135, doi: 10.1034/j.13990012.2001.150209.x, indexed in Pubmed: 11264640. 
23. Longia GS, Kumar V, Gupta CD. Intrarenal arterial pattern of human kidney-corrosion cast study. Anat Anz. 1984; 155(1-5): 183-194, indexed in Pubmed: 6721181.

24. Młynarczyk L, Wożniak W, Kieresz A. Varianten in der Anzahl und im Verlauf der Nierenarterien. Anat Anz. 1966; 118: 67-81.

25. Novick AC, Magnusson M, Braun WE. Multiple-artery renal transplantation: emphasis on extracorporeal methods of donor arterial reconstruction. J Urol. 1979; 122(6): 731-735, indexed in Pubmed: 390168.

26. Papaloucas C, Fiska A, Demetriou T. Additional renal arteries. Clin Anat. 2007; 20(4): 475, doi: 10.1002/ca.20465, indexed in Pubmed: 17309064.

27. Patil ST, Meshram MM, Kasote AP. Bilateral malrotation and lobulation of kidney with altered hilar anatomy: a rare congenital variation. Surg Radiol Anat. 2011; 33(10): 941-944, doi: 10.1007/s00276-011-0826-6, indexed in Pubmed: 21626276.

28. Patil UD, Ragavan A, Murthy K, et al. Helical CT angiography in evaluation of live kidney donors. Nephrol Dial Transplant. 2001; 16(9): 1900-1904, indexed in Pubmed: 11522876

29. Reis RH, Esenther G. Variations in the pattern of renal vessels and their relation to the type of posterior vena cava in man. Am J Anat. 1959; 104: 295-318, doi: 10.1002/ aja.1001040206, indexed in Pubmed: 14437208.

30. Rossi UG, Romano M, Ferro C. Seven renal arteries. Clin Anat. 2006; 19(7): 632-633, doi: 10.1002/ca.20264, indexed in Pubmed: 16372339.

31. Sagban TA, Baur B, Schelzig $H$, et al. Vascular challenges in renal transplantation. Ann Transplant. 2014; 19: 464-471, doi: 10.12659/AOT.890893, indexed in Pubmed: 25234743.
32. Saldarriaga B, Pérez AF, Ballesteros LE. A direct anatomical study of additional renal arteries in a Colombian mestizo population. Folia Morphol. 2008; 67(2): 129-134, indexed in Pubmed: 18521812.

33. Sampaio FJ, Passos MA. Renal arteries: anatomic study for surgical and radiological practice. Surg Radiol Anat. 1992; 14(2): 113-117, doi:10.1007/bf01794885, indexed in Pubmed: 1641734

34. Satyapal KS, Haffejee AA, Singh B, et al. Additional renal arteries: incidence and morphometry. Surg Radiol Anat. 2001; 23(1): 33-38, doi:10.1007/s00276-001-0033-y, indexed in Pubmed: 11370140.

35. Shakeri $A B$, Tubbs RS, Shoja MM, et al. Bipolar supernumerary renal artery. Surg Radiol Anat. 2007; 29(1): 89-92, doi: 10.1007/s00276-006-0158-0, indexed in Pubmed: 17061029.

36. Shoja MM, Loukas M, Etemadi J, et al. Letter: Multiple renal vessels associated with testicular vessels. Surg Radiol Anat. 2011; 33(6): 557, doi:10.1007/s00276-011-0811-0, indexed in Pubmed: 21479598.

37. Singh $D$, Finelli $A$, Rubinstein $M$, et al. Laparoscopic partial nephrectomy in the presence of multiple renal arteries. Urology. 2007; 69(3): 444-447, doi:10.1016/j. urology.2006.10.047, indexed in Pubmed: 17382140.

38 . Sykes $D$. The arterial supply of the human kidney with special reference to accessory renal arteries. Br J Surg. 1963; 50: 368-374, doi:10.1002/bjs.18005022204, indexed in Pubmed: 13979763.

39. Vaccarisi S, Bonaiuto E, Spadafora N, et al. Complications and graft survival in kidney transplants with vascular variants: our experience and literature review. Transplant Proc. 2013; 45(7): 2663-2665, doi: 10.1016/j.transproceed.2013.07.007, indexed in Pubmed: 24034018. 